\title{
Incidence and significance of traumatic mediastinal
} haematoma ${ }^{1}$

\author{
FRANCIS SANDOR \\ From Hartlepools Hospital, Hartlepool, Co. Durham
}

\section{'Observare necesse est'}

So far the clinical diagnosis of mediastinal haematoma has been rare. A few cases have been reported after a fall from a height (Körner, 1915 ; Schmitt, 1940 ; Vincent, Roche, and Michel, 1953), crush injury of the chest (Zimmerman, 1936; Longin, 1955), or after a penetrating injury of the chest (Horn, 1930 ; Hanner and Glauser, 1953 ; Williams, 1959 ; Cohen, 1958).

The source of bleeding was believed to be the torn mediastinal veins, the marrow of the broken sternum or vertebrae (Eiselsberg and Gold, 1931), or, in penetrating injuries, the internal mammary artery or vein (Horn, 1930). The characteristic radiological finding was a bilateral widening of the mediastinum with sharply defined margins above the heart. The clinical findings were inconclusive. The opacities disappeared within two to three weeks. The haematoma, large enough to be almost exsanguinating, was rapidly absorbed. Until recently, when cardio-respiratory distress (Laforet, 1955; Thomas and Keeling, 1956), even fatal delayed shock (Vincent et al., 1953), complicated some cases, no treatment was recommended. Thomas and Keeling (1956) performed anterior mediastinotomy; Hanner and Glauser (1953) and Coté, Hodgson, and Ellis (1959) removed organizing haematomata from the mediastinum.

Endress (1953) believed that this lesion is far more common than is reported. The diagnosis has been missed partly because radiographs of the chest were not taken in cases where fractures of the thoracic cage were not suspected and partly because, when suspected, the films were taken with the 'rib technique', which did not demonstrate these opacities. When radiographs of the chest were taken antero-posteriorly from a short distance with the portable apparatus, such distortions 1Part of a project carried out with a grant from the Newcastle
Regional Hospital Board of the mediastinal shadow were expected that the opacities were dismissed. In some patients the opacity was situated lower (Vincent et al., 1953) and pericarditis was diagnosed.

\section{TRAUMATIC RUPTURE OF THE AORTA}

There were numerous earlier necropsy reports of patients who died of clinically undiagnosed traumatic rupture of the aorta (T.R.A.), and in each case a massive mediastinal haematoma was found.

Clinical diagnosis was first made by Hollingsworth, Johnston, and McCooey (1952), who described the widening of the mediastinum as a sign of T.R.A. Further radiological signs were described by Wyman (1953), such as displacement of the mediastinal surface of the lungs, irregularity and obscuration of the aortic outline as it was doubled or trebled by fluid and coagulated blood ('layering effect'). Passaro and Pace (1959) found that the tracheal air shadow was more pronounced in contrast to the surrounding fluid density.

None of these signs was specific and they could be caused by a mediastinal haematoma of other than aortic source (Wyman, 1953). Yet Le Brigand. Binet, and Langlois (1961) believed that widening of the mediastinum was for all practical purposes the only sign of T.R.A.

\section{INVESTIGATIONS AND CLASSIFICATION}

Within a short period of two years four cases (cases 1 to 4) came under clinical observation (with fatal outcome). In two (cases 2 and 4), T.R.A. was clinically and radiologically diagnosed, whereas in the two others (cases 1 and 3), the diagnosis of non-aortic mediastinal haematoma was only made at necropsy.

Investigations were started to find the relative incidence and clinical significance of non-aortic mediastinal haematoma, and at the same time a search was made for further differentiating signs of the mediastinal opacity. During a period of five 
years, radiographs of the chest were taken of all patients who sustained major multiple injuries irrespective of whether they had chest injuries or not. When widening of the mediastinum was noted further radiographs were taken using the same technique to see how these opacities changed their shape and whether they disappeared. The films were compared with those of known cases of T.R.A. in order to avoid mistakes.

The diagnosis of non-aortic mediastinal haematoma was made in 12 patients (cases 5 to 16), two of whom died. No further case of T.R.A. came under observation and late follow-up films showed that no patient developed a false aneurysm.

It was noted that in some patients the supracarinal part of the trachea became deviated to the right though the cervical trachea remained central. They all had a large mediastinal opacity, indistinguishable from that of known cases of T.R.A. When the opacity began to diminish the trachea was seen to return to its central position. It was concluded that in these cases bleeding arose from the small branches of the aorta (bronchial, oesophageal, and intercostal) and the pressure of the haematoma was only sufficient for local displacement of the trachea.

In other cases the trachea remained central throughout. T.R.A. was excluded irrespective of the size or shape of the opacity. These haematomata were mediastinal or paramediastinal in situation and bleeding arose from broken ribs or vertebrae or from mediastinal veins.

These 16 patients are presented in three groups: Group A, traumatic rupture of the aorta: two cases (cases 2 and 4); Group B, periaortic mediastinal haematoma: six cases (cases $1,5,7,13,14$, and 15) ; and Group C, miscellaneous mediastinal and paramediastinal haematoma: eight cases (cases 3, 6, 8, 9, 10, 11, 12, and 16).

\section{GROUP A. TRAUMATIC RUPTURE OF THE AORTA}

(ASE 2 R. C., a man aged 29, was knocked down by a car and sustained compound fractures of all four limbs. On arrival at hospital he was unconscious and pulseless. After resuscitation it was noted that the trachea was deviated to the right and the apex beat was felt in the right parasternal line. No other abnormal signs were found. Open reduction of the compound fractures was performed and the patient recovered from general anaesthesia.

Next day the whole of the left hemithorax was dull and without breath sounds. Using an underwater seal, $2,000 \mathrm{ml}$. of blood was drained and transfusion was continued. The trachea and apex beat were felt in the normal position, but the patient gradually became drowsy and comatose due to massive fat embolism.
Fourteen hours after admission a radiograph of the $\overrightarrow{\vec{N}}$ chest (Fig. 1a) showed a massive mediastinal opacity, $\frac{\vec{\sigma}}{\sigma}$ and the diagnosis of T.R.A. was made. However, the patient was still comatose and developed severe hypertension $(295 / 190 \mathrm{~mm} . \mathrm{Hg})$, anuria, and uraemia.

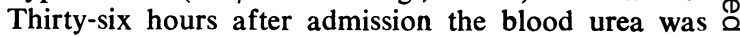
$240 \mathrm{~mm}$. $/ 100 \mathrm{ml}$. He was treated with $50 \%$ dextrose using an intracaval catheter which improved diuresis. Next day he was conscious and answered questions.

Seventy-two hours after admission he was fully conscious. Repeated radiographs showed that the opacity had decreased in size to less than half of the original (Fig. 1b). The intercostal tube was therefore removed. Six hours later he collapsed and died.

At necropsy there was an almost complete rupture of the aorta just below the ligamentum arteriosum, with wide separation of the two ends. The intima was normal. The left pleura was full of blood.

Comments : As the intercostal tube was in situ and there was no bleeding, diminution of the opacity could only be explained by dispersion and absorption of the haematoma.

CASE 4 T. K., a man aged 52, was pulling a heavy cable when he felt a sudden pain in the back and collapsed. He became cold and clammy, pulse 72/ min., blood pressure $120 / 70 \mathrm{~mm}$. Hg. The trachea was central. There was tenderness on pressure over the spinous processes of $D_{5}$ and $D_{6}$ vertebrae and guarding in the epigastrium. He had mild glycosuria. Radiographs showed osteoarthritic changes of the dorsal spine (Figs 2b, 2c) and a prominent aortic knuckle (Fig. 2a), though the film was slightly rotated.

After sedation his blood pressure rose to $200 / 130$ $\mathrm{mm}$. Hg. For one week he was pyrexial and pain was almost continuous. Serum amylase was normal. He remained hypertensive, $240 / 120 \mathrm{~mm}$. Hg. On the tenth day, slight deviation of the trachea to the right was noticed. A radiograph then showed a typical false aneurysm of the aorta (Fig. 2d). He was transferred to the Thoracic Centre. At thoracotomy a large haematoma was found along the whole course of the aorta. Dissection of the mediastinum was not possible and the chest was closed.

The patient remained hypertensive. Thirty-seven days after the accident he died of secondary haemorrhage. Necropsy confirmed a partial tear of the aorta.

Comments: On retrospective analysis of the films it was noted that the infraclavicular (supracarinal) part of the trachea was deviated to the right to such a degree that the left, instead of the right, main bronchus became its direct continuation (Fig. 2b). This sign has not, so far, been described and became the basis of our classification. The lateral film (Fig. 2c) showed an ovoid opacity arising from the anterior surface of the aortic arch, indicating the site of the mediastinal haematoma.

GROUP B. PERIAORTIC MEDIASTINAL HAEMATOMA

CASE 1 R. E., a miner aged 61 , was crushed in the pit and was moribund on arrival. He had a stove-in 


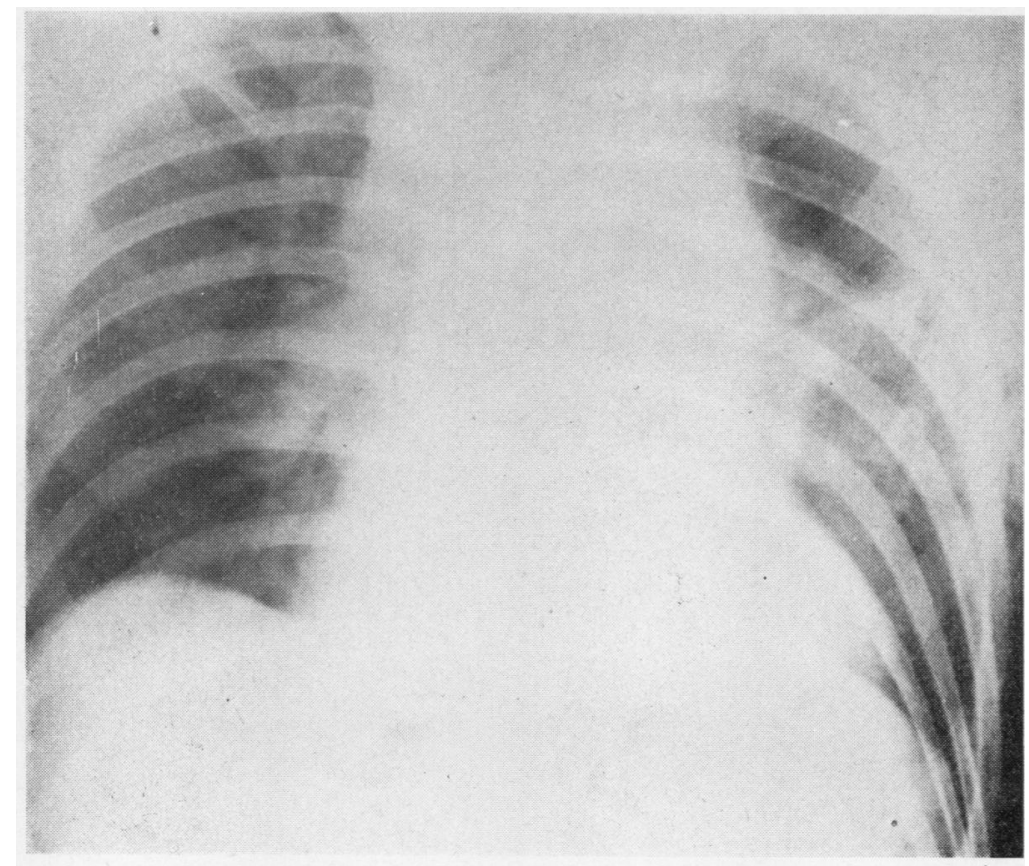

FIG. 1. Case 2. Rupture of the aorta. (a) 14 hours after admission. Large dense mediastinal opacity with sharply defined convex margins. Note right upper mediastinal opacity. (b) After 72 hours. Marked diminution of the opacity by absorption and dispersion of the haematoma (note opacities on the right side). Intercostal tube in situ.

(a)

(b)

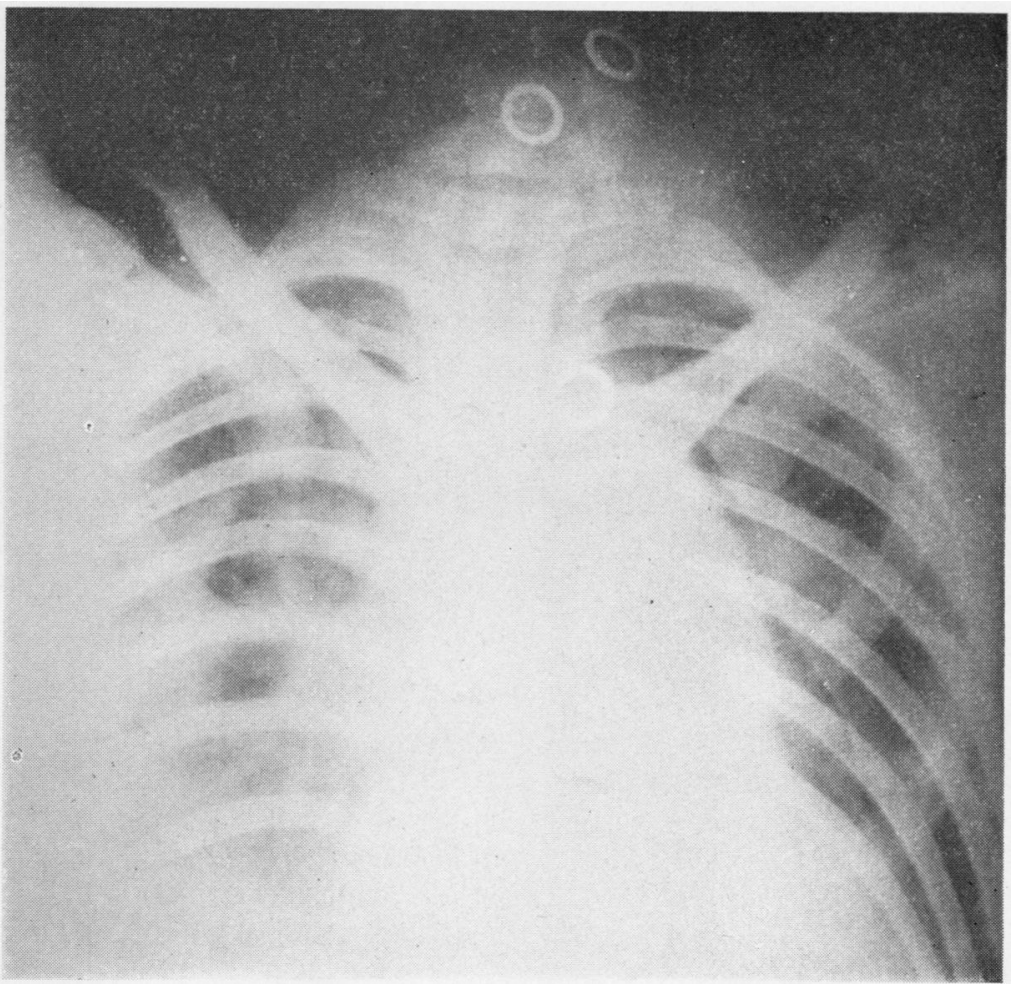




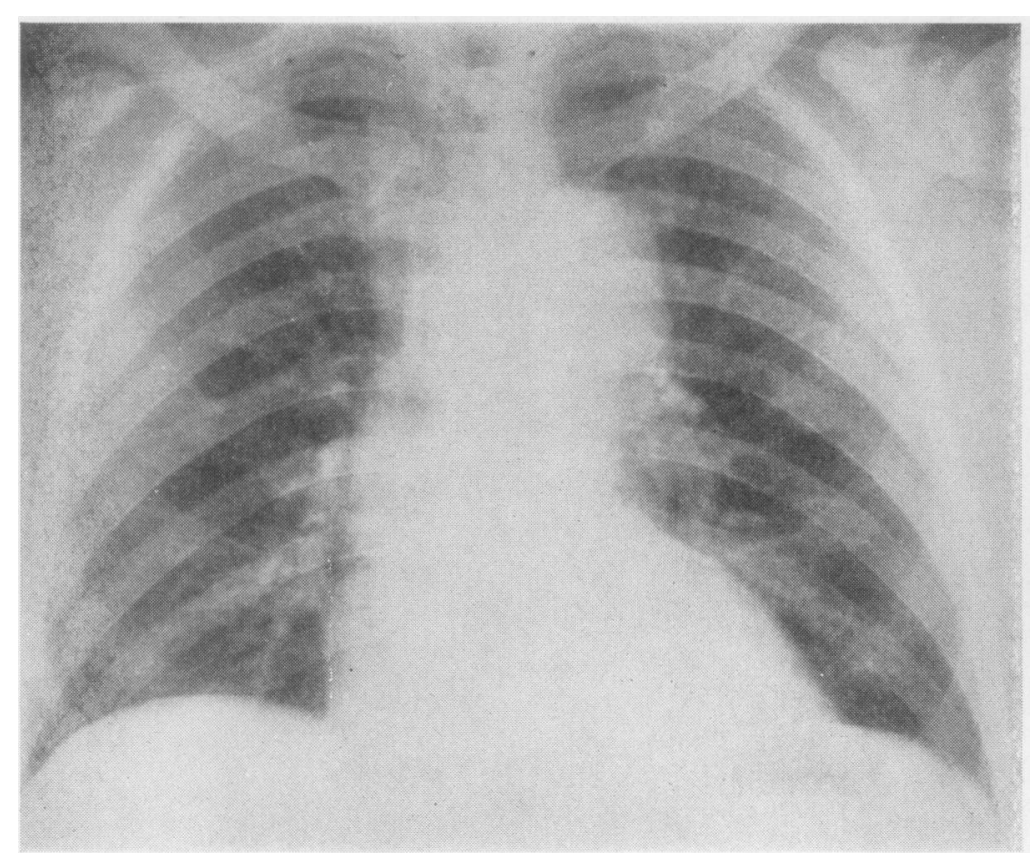

FIG. $2 \mathrm{a}$

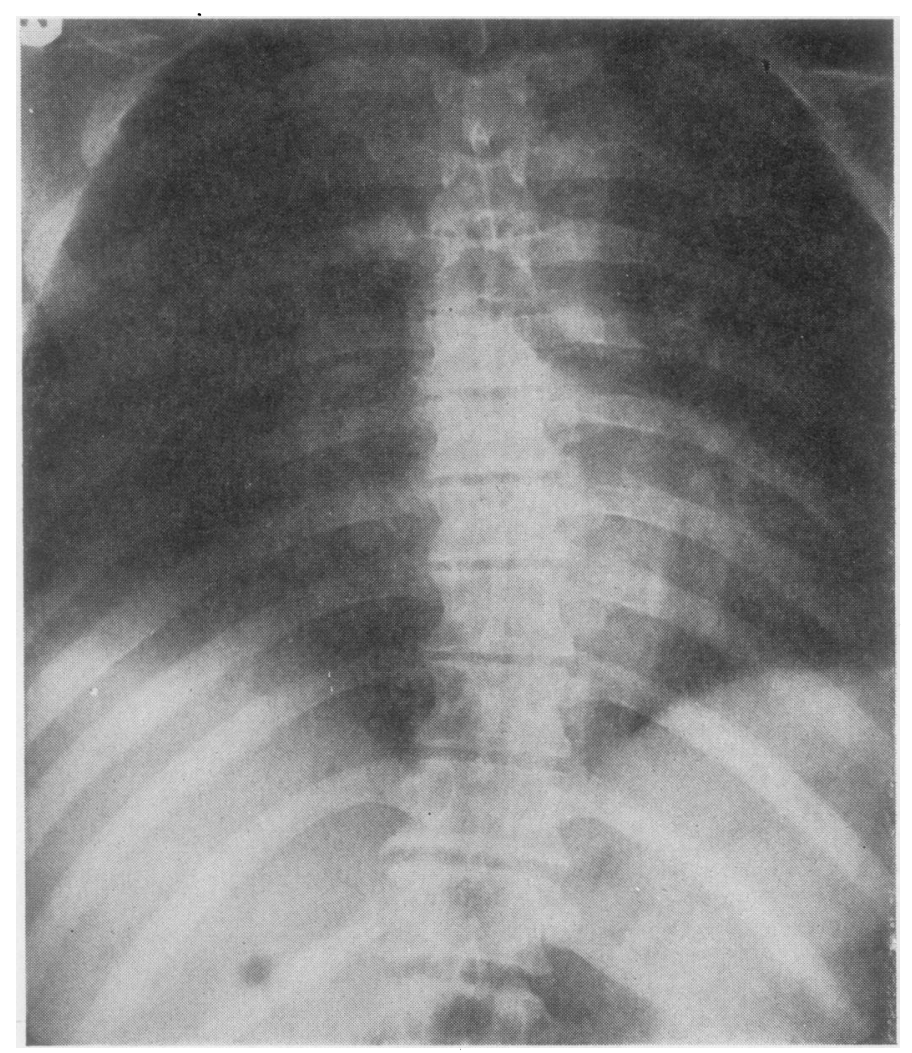

FIG. 2b 


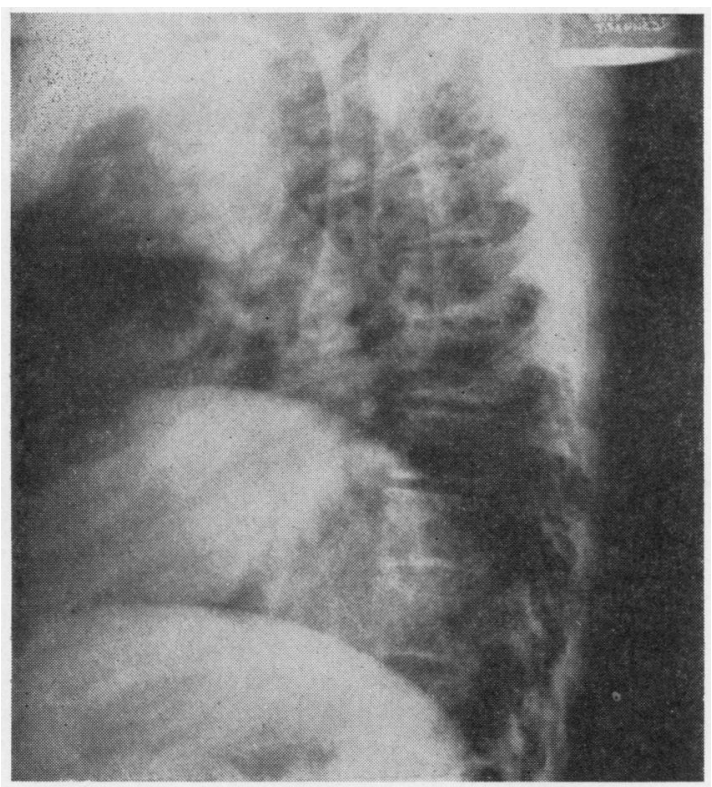

FIG. 2. Case 4. Rupture of the aorta. (a) On admission. Prominent aortic knuckle. Note right upper mediastinal opacity. The trachea (cervical) is central. (b) Penetrating A.P. film on admission. Note contrast of the tracheal air shadow against the surrounding density, and deviation of the supracarinal part of the trachea to the right to such a degree that the left bronchus became its direct continuation. (c) Penetrating lateral film on admission. Ovoid dense shadow arising from the aortic arch extending upwards, anteriorly. (d) 10 days later. The false aneurysm is bulging into the left lung field. Note also right upper mediastinal opacity.

FIG. 2 c

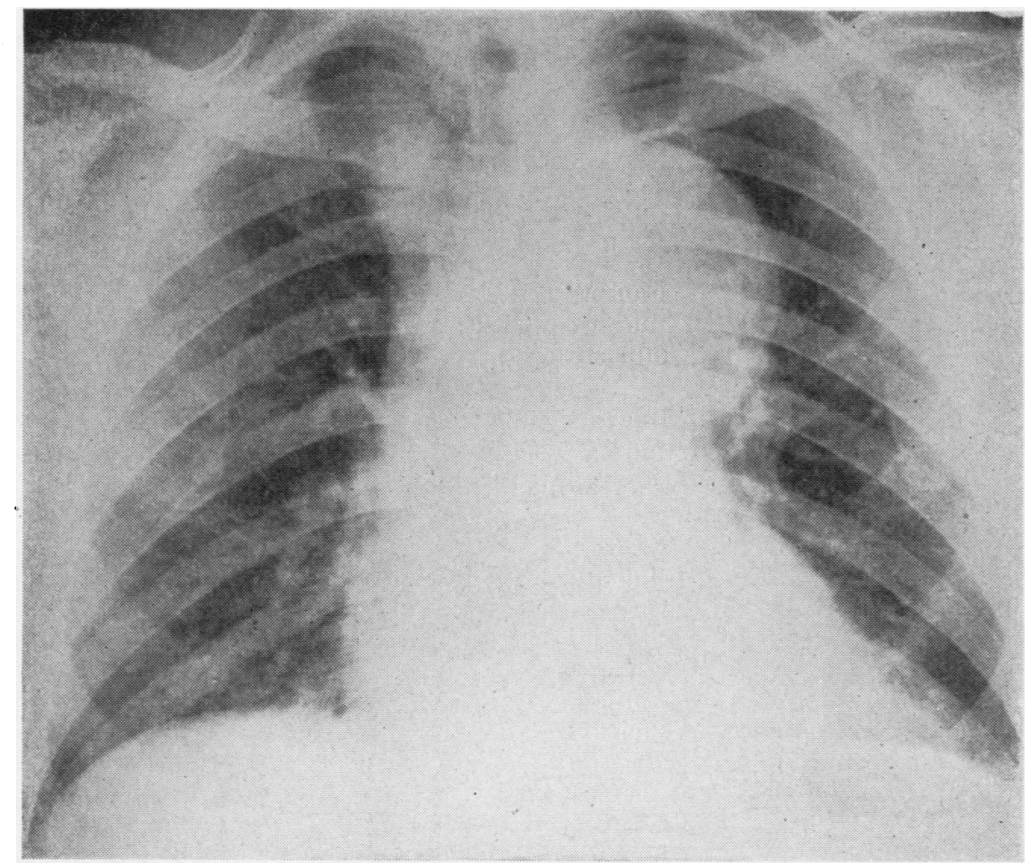

FIG. 2d 
chest and multiple fractures of the pelvis and died within minutes. At necropsy rupture of the right leaf of the diaphragm and prolapse of the liver into the right pleura were found. 'The most significant finding and that responsible for death was a large paraaortic haematoma which surrounded the whole of the thoracic aorta. The intima of the aorta was intact and there was no tear of the lungs. Haemorrhage arose from the shearing strain of the protruding broken ribs on the small branches of the aorta in the course of their passage through the wall. (L. Grant Leitch).'

Comments: These findings were identical with the operative findings of case 4 , though the aorta was intact.

CASE 5 G. D., a woman aged 62, was knocked down by a car and sustained multiple compound fractures and lacerations. She was pale and complained of severe pain in the left side of the chest and in the left hypochondrium, where guarding and tenderness were found. $\mathrm{Hb} 74 \%$.

A radiograph of the chest showed fractures of the first, second, and third left ribs and a large mediastinal opacity including the aortic knuckle. The trachea, which was central at its cervical part, was deviated to the right just above the carina (Fig. 3).

After admission the pain in the left hypochondrium became severe and she vomited. After three pints of blood had been transfused the haemoglobin wase estimated at $62 \%$.

Laparotomy was performed, but there was only a large retroperitoneal haematoma behind and to the right of the duodenum. The abdomen was closed. Debridement and manipulations were performed $\mathscr{Q}$ while she received another 3 pints of blood.

Her voice was high-pitched for one week. Fourmore pints of blood restored a normal haemoglobin? level. Repeated radiographs showed marked diminu- $\overrightarrow{\vec{H}}$ tion of the mediastinal opacity, the margins of which became sharply outlined. She was progressing well, but four weeks later she suddenly collapsed and died. At necropsy a considerable amount of blood clot was found in the branches of both pulmonary arteries.Both lower lobes were collapsed. Neither the retro- $\vec{\omega}$ peritoneal nor the mediastinal haematoma was men-o tioned in the report, probably because they had been? absorbed.

Comments: Unaccountable blood loss and lefe epigastric pain simulated rupture of the spleen in this case. This occurred also in some cases of T.R.A (Murdock, 1957 ; Zehnder, 1960).

CASE 7 E. W. W., a man aged 76, was knocked down by a car and sustained multiple compound fractures and large haematomata. A radiograph of the ches? taken in the supine position (Fig. 4a) showed a large dense mediastinal opacity including the aortico knuckle and the right border of the heart. Tho

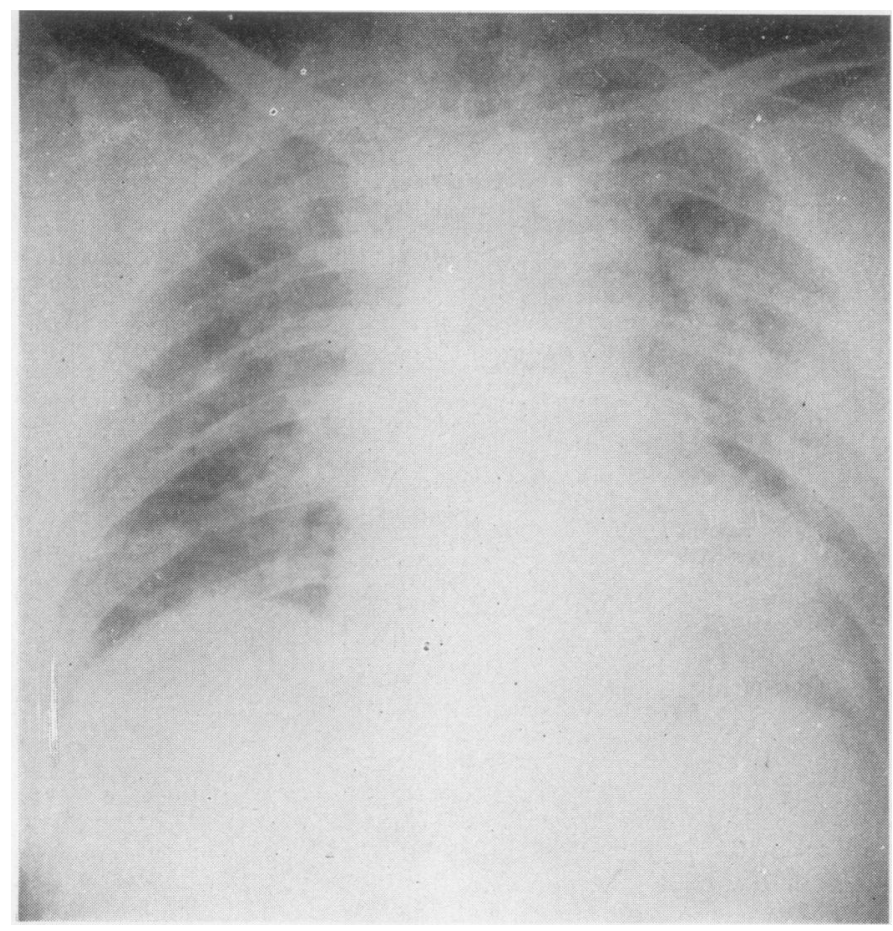

FIG. 3. Case 5. Large dense mediastinal opacity including the aortico knuckle. The intrathoracic trachea is faintly seen to be deviated to then right. 


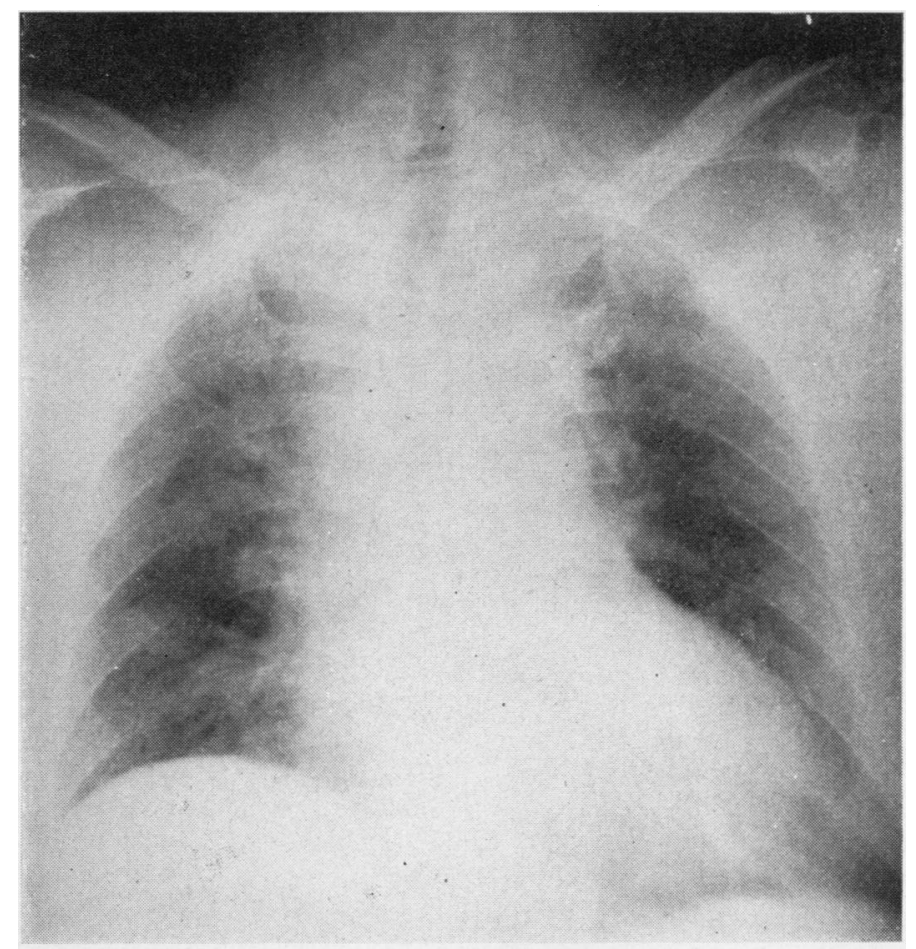

FIG. 4a

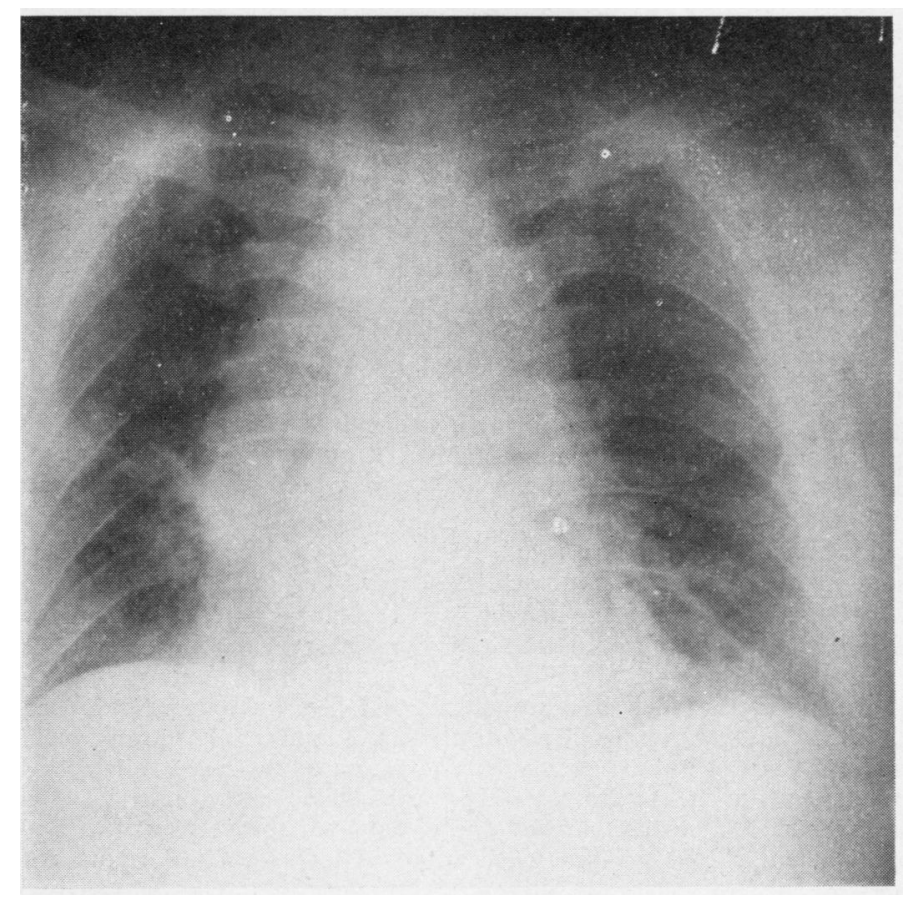

FIG. $4 b$

For legend see p. 50. 


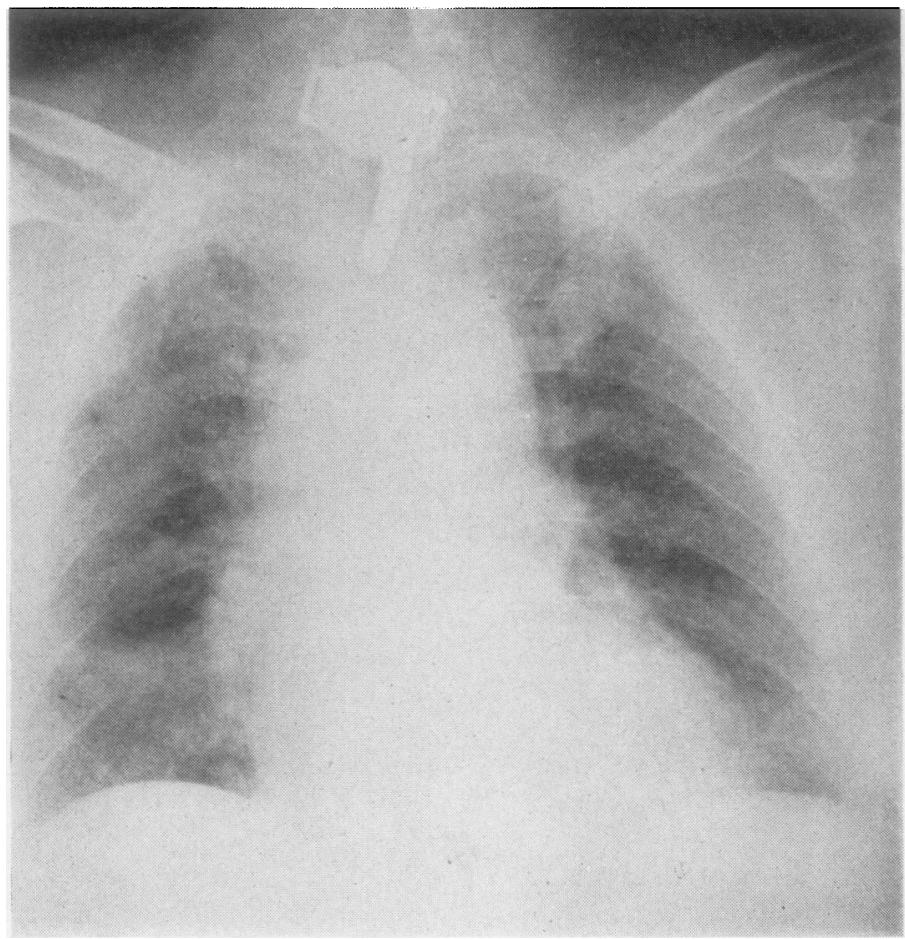

IFIG. $4 \mathrm{C}$

FIG. 4. Case 7. (a) Supine A.P. film on admission. Note large dense mediastinal opacity from the clavicles to the diaphragm, including the aortic shadow and the right border of the heart; deviation to the right of the intrathoracic trachea. (b) Upright A.P. film nine days later. Note conical shape of the opacity (effect of gravity). The right border of the heart is seen through the opacity. (c) 10 days after admission. The direction of the tracheostomy cannula indicates the deviation to the right of the intrathoracic part of the trachea (compare with Fig. $9 b$ ).

intrathoracic trachea was deviated to the right to such an extent that the left instead of the right main bronchus became its direct continuation. After resuscitation open reductions of fractures were performed. Haematuria subsided within four days. 'Pneumonia' was treated with antibiotics, and one week later he was afebrile.

On the following day his condition deteriorated, he became febrile, dyspnoeic, cyanosed, and confused. A portable film taken in the upright position, in which he was nursed throughout (Fig. 4b), showed that the opacity was now conical in shape, probably due to gravity. Tracheostomy was performed because the patient become unconscious, and on regular aspiration consciousness returned.

On the radiograph taken on the tenth day (Fig. $4 c$ ), the direction of the cannula clearly showed the deviation of the infraclavicular part of the trachea to the right. Next day he became severely oliguric ; his blood urea rose to $180 \mathrm{mg} . \%$. He was transferred to the artificial kidney unit at the Royal Victor Infirmary, Newcastle upon Tyne, where haemgdialysis was performed. He died 20 days after the accident. Necropsy was not performed.

Comments: Such conical opacities have sever요 times been diagnosed as 'pericarditis' (Brown, Torf sykoski, and Stevens, 1953 ; Vincent et al., 1953).

CASE 13 D. L., a man aged 59, was knocked down a car and sustained multiple pelvic fractures includ ing central dislocation of the left femur, large haematomata, and paralysis of the left lateral poptteal nerve. He was confused and cyanosed and hal air hunger. The urine was blood-stained. A radiograph of the chest showed a large column-like opacit in which the tracheal air shadow was seen to deviated to the right just above the carina (Fig. 5a)

After resuscitation the fractures were treated. Agr hunger was aggravated by ileus which was treatef with gastric aspirations for one week. He began to 


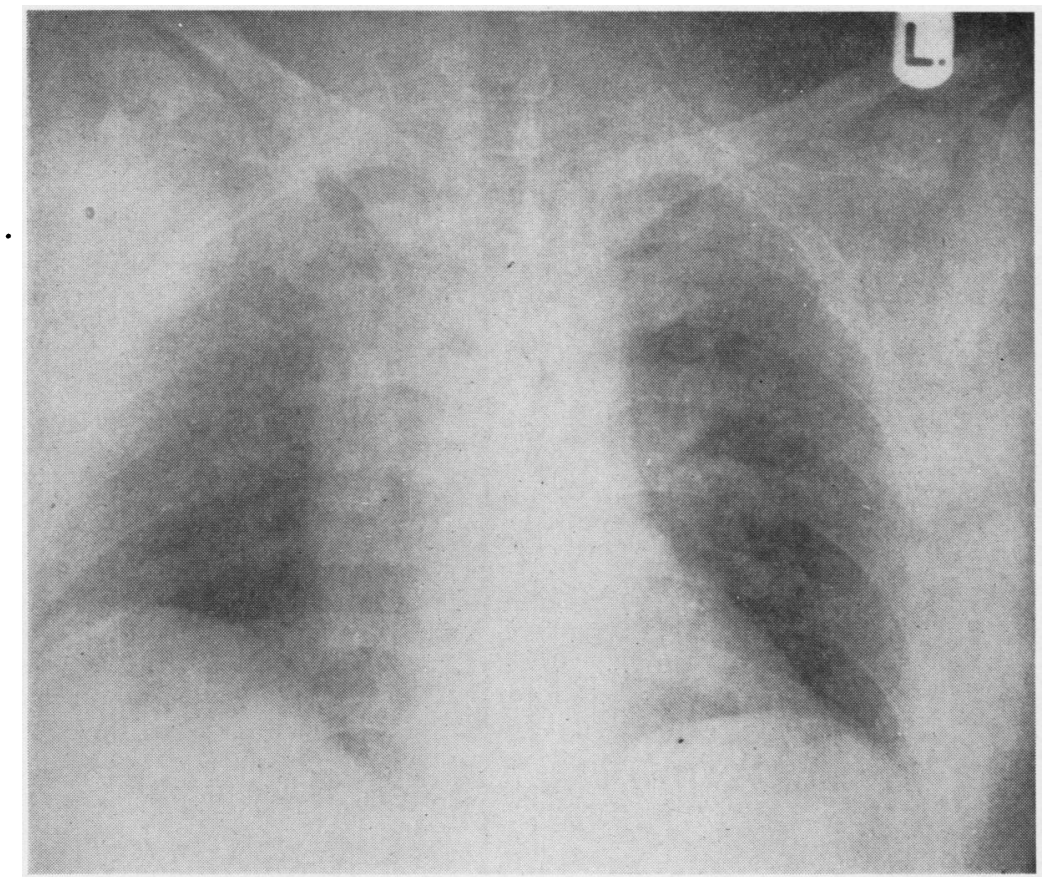

FIG. 5a

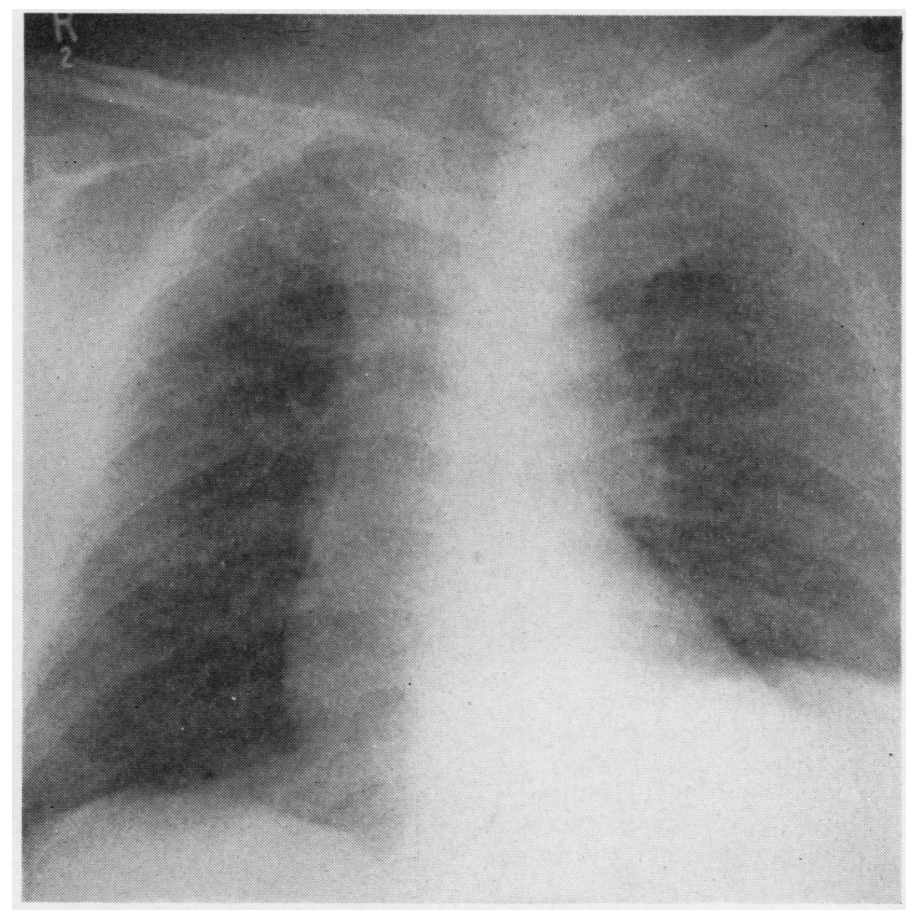

FIG. $5 b$

For legend see p. 52. 


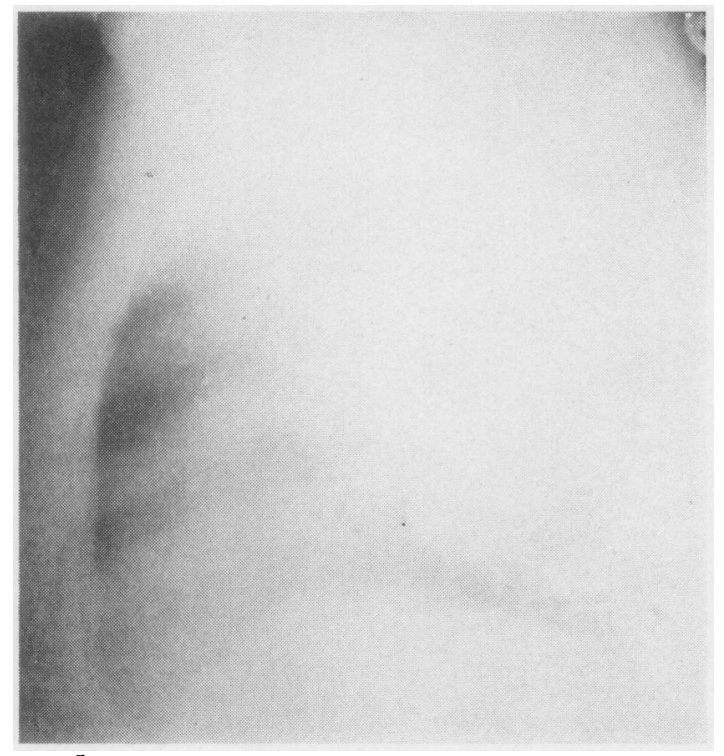

FIG. $5 \mathrm{c}$

FIG. 5. Case 13. (a) On admission. Large column-like mediastinal shadow extending from the clavicles to the diaphragm. The intrathoracic deviation of the trachea to the right is faintly seen. (b) 12 days later. 'Waist' formation by dispersion of the haematoma at the level of the aortic arch. (c) Lateral film. The haematoma is posterior and occupies almost the whole of the lung field.

improve and made a good recovery. After one year he was walking without any appliance. Serial radiographs showed diminution of the opacity with a 'waist' at the level of the aortic arch (Fig. 5b), and when this was complete the upper part of the opacity became a 'right upper wedge-shaped opacity' which was seen in all cases in the final stage of absorption. The lateral film showed that the opacity was posterior in situation and it almost completely occupied the lung field (Fig. 5c).

Comments: The initial film was indistinguishable from that of known cases of traumatic rupture of the aorta.

CASE 14 W. A. Y., a man aged 51, was knocked down by a car and sustained multiple fractures of the pelvis and sacrum and various lacerations. $\mathrm{He}$ was severely shocked and for five days he had the same type of air hunger as the previous patient. His fractures healed and he recovered.

A radiograph of the chest could be compared with an earlier one which was normal. There was a large dense bulging opacity in which the trachea was faintly seen to be deviated to the right just above the carina (Fig. 6a). Twelve days later the trachea was central and 'waist' formation was evident on the radiograph (Fig. 6b).

Comments : A late follow-up film of the chest was identical with the pre-accident film.
CASE 15 J.C., a man aged 85, fell and sustained pertrochanteric fracture of the right femur. He was drowsy and confused on admission. His blood pres sure was $170 / 90 \mathrm{~mm}$. Hg. Haemoglobin $62 \%$. Blood urea $102 \mathrm{mg} . \%$. His blood urea rose to $145 \mathrm{mg} . \%$ He remained unconscious. Five days later the bloof urea decreased to $128 \mathrm{mg} . \%$. His haemoglobin was. $52 \%$. After 3 pints of blood had been transfused his general condition improved and he regained con $\overrightarrow{\vec{A}}$ sciousness. Traction was applied and he made a good recovery. Haemoglobin and blood urea remaines normal throughout. An admission radiograph of the chest (Fig. 7) showed a large dense mediastinafo opacity with sharply defined convex margins, remin-iscent of a false aneurysm (compare with Fig. 2d) Serial radiographs showed diminution of the opacity according to the pattern described in the previou? case reports. One year later there was only a wedgeshaped right upper mediastinal opacity present.

Comments: The patient had no appreciable frace ture haematoma and no other injuries; anaemia wa caused by loss of blood into the mediastinum. On the other hand, uraemia began to improve before the anaemia was corrected. Its cause could only be the् initial renal vasoconstriction.

\section{GROUP C. MISCELLANEOUS MEDIASTINAL AND PARAMEDIASTINAL HAEMATOMA}

\section{CERVICO-MEDIASTINAL HAEMATOMA}

Case $3^{2}$ C. M., a man aged 74, fell down the stairs and sustained an extension fracture of $\mathrm{C}_{4}$ and $\mathrm{C}_{6}$ vertebrae. He developed stridor dysphagia, swelling of the neck, and bruisings of the posterior pharyngeal wall and the faucial pillars. These symptoms soon disappeared, but he then developed bruises over the anterior chest wal which extended down to the nipples. His condition was satisfactory six days after the accident, when he had a sudden fit of coughing and died. At necrops haemorrhagic infiltration of the carotid sheath an superior mediastinum was found, which extended upwards to the base of the skull. There was aboup $200 \mathrm{ml}$. of blood in front of the broken vertebrae, but blood loss was not significant and the infiltration was 'thin'. The anterior common ligament and the pre vertebral fascia were torn. There was no blood in tho extradural space and the airways were clear. Death was presumably due to vagal shock.

Comments : Although the haemorrhage was venous (from the body of the broken vertebrae), it infiltrate $\Phi$ widely irto the mediastinum through the tear of the anterior common ligament and the prevertebra fascia which opened up the visceral space. From here the blood reached the subcutaneous tissues through normal anatomical pathways (Grodinsky and Holyo oke, 1938). There are no such pathways outside the visceral space and even the high pressure haema toma of an aortic tear remains confined in the ches by Sibson's fascia.

${ }^{2}$ See British Journal of Surgery (1964, 51, 682). By kind permission of the Editor. 
FIG. 6. Case 14. (a) Two days after the accident. Large dense mediastinal opacity with fairly sharply defined convex margins. Note deviation of the intrathoracic trachea to the right. (b) Two weeks later. Marked diminution of the opacity. 'Waist' formation almost complete, leaving the 'right upper wedge-shaped opacity'. The trachea has a straight course throughout. 


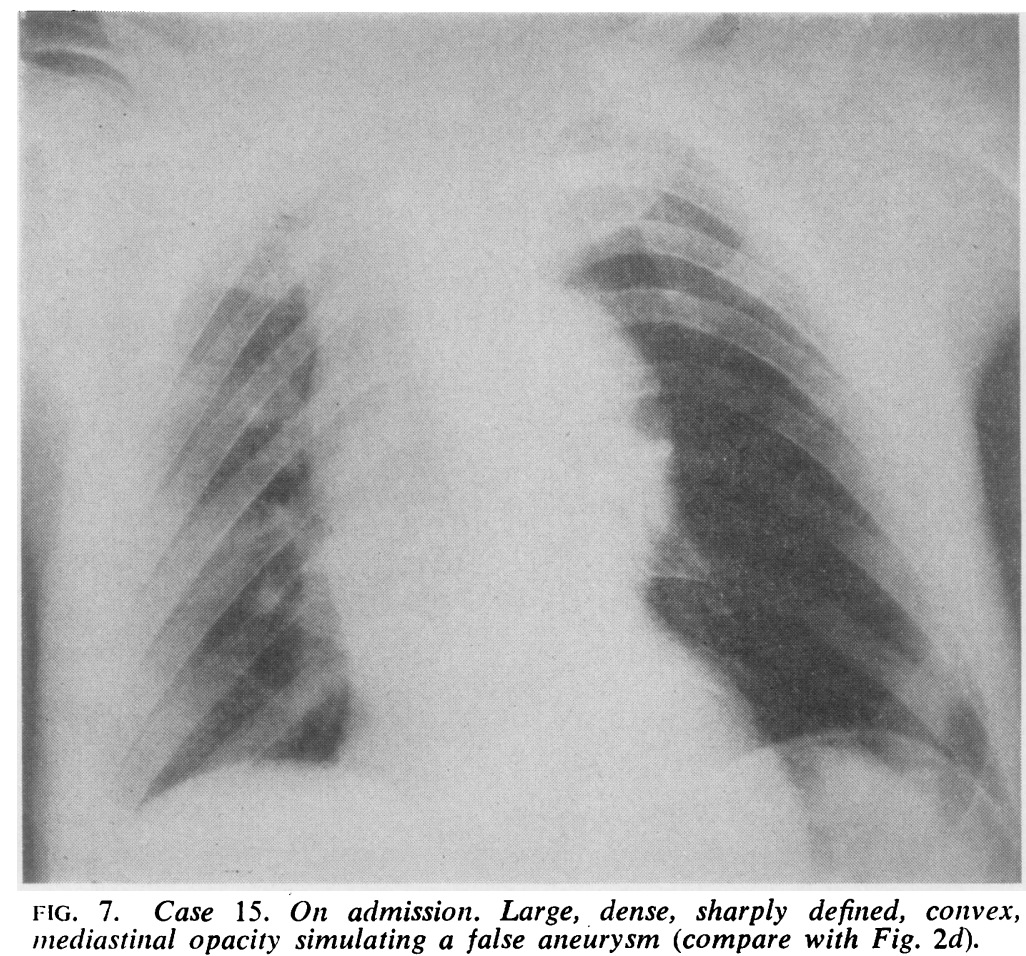

\section{PARAVERTEBRAL HAEMATOMA}

Case 6 V.D.C., a man aged 19, was knocked off his motorcycle and sustained concussion, multiple lacerations, and fractures. There was tenderness on pressure over $D_{3}$ and $D_{4}$ vertebrae. Sensation and movements of the limbs were normal. A radiograph showed a fracture dislocation of $D_{3}$ vertebra on $D_{4}$ and also a fusiform paravertebral opacity, widest at this level, which merged with the shadow of the descending aorta. Two days later a radiograph of the chest showed a large dense mediastinal opacity; the trachea was straight (Fig. 8). The opacity disappeared after one week. The patient has fully recovered.

Comments : Eiselsberg and Gold (1931) described this type of fracture haematoma. While the anterior common ligament prevents its forward spread, it can spread on both sides and produces a fusiform opacity, similar to a paravertebral abscess. The haematoma can spread forwards on both sides later on, thus displacing the mediastinal pleura, and on the radiograph it contrasts with the air-containing lungs. The opacity is dense because its greatest diameter is antero-posterior, but it is not voluminous and is quickly absorbed.

\section{VENOUS HAEMATOMA}

Case 16 J. J. R., a man aged 60, was knocked down by a train and sustained concussion and multiple fractures. He was severely shocked, $\frac{3}{\sqrt{3}}$ sweating, and cyanosed and remained restless and confused. After resuscitation he was conscious but became drowsy and finally comatose. He was transferred to the Department of Neurosurgery at Middlesbrough General Hospital. No intracranialx haemorrhage was found. A tracheostomy was per-윽 formed and he regained consciousness after one. week. He fully recovered. The admission radiographô showed fractures of the second to fifth left ribs and₹ linear and patchy opacities in the right upper lobe.응 The trachea was straight and on its right side, parallel with it, there was a faint vertical opacity of uniformo density (Fig. 9a). Next day (after tracheostomy) this opacity was seen to be denser and more obvious $; N$ the direction of the cannula confirmed that the intrathoracic part of the trachea was straight (Fig. $9 b^{3}-$ N compare with Fig. 4c). Serial radiographs showedw 'waist' formation and finally complete absorption of the opacity.

Comments : This opacity developed slowly, though it extended ultimately over an extensive area. The $\stackrel{\rho}{+}$ bleeding was probably venous, from the tributaries 0 of the superior vena cava. Twenty-one months later a $\overrightarrow{0}$ portable film was taken after a major abdominalब

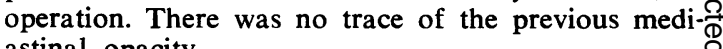
astinal opacity.

${ }^{3}$ The film was made available by courtesy of Mr. P. R. R. Clarkeo 


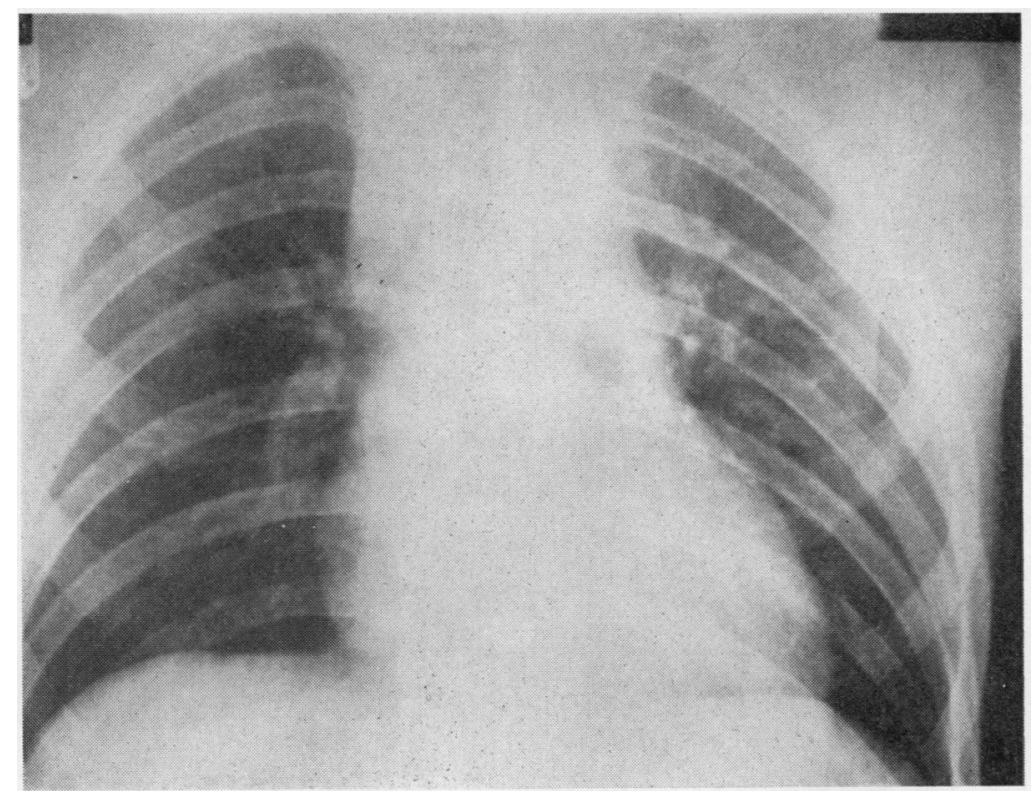

FIG. 8. Case 6. Paravertebral haematoma spreading forward into the mediastinum. The fusiform dense paravertebral shadow is seen through the mediastinal opacity.

\section{PARAMEDIASTINAL HAEMATOMA}

Case 10 G. H., a boy aged 17, fell off his motorcycle and sustained severe concussion, multiple compound fractures, and a tear of the axillary artery and of the brachial plexus. He was deeply shocked and unconscious. There was a large axillary haematoma. A radiograph of the chest showed fractures of the first, second, and third right ribs and a large right paramediastinal haematoma which occupied almost the whole of the right apical region. After resuscitation he was transferred to the Department of Vascular Surgery, Newcastle upon Tyne. Paralysis of the brachial plexus persisted; otherwise he recovered fully.

Comments : This paramediastinal haematoma arose from the broken ribs. It remained distinct from the axillary haematoma ; it was confined to the chest by Sibson's fascia.

Case 11 A. R., a man aged 58, had a cervico-dorsal sympathectomy. Following this he developed a haematoma which was evacuated. Radiography of the chest showed a dense right upper paramediastinal opacity with sharply defined convex borders (Fig. 10) which on the lateral film was seen to be distinct from the aorta.

Comments : At operation Sibson's fascia was transected and the haematoma bulged into the neck. This was the only case where the opacity extended above the clavicle.
Case 12 E. B., a woman aged 75 , was knocked down by a car and sustained bruises over the chest and a fracture of the ilium. She recovered and was discharged after one week. An admission radiograph showed a widened mediastinum due to a right upper mediastinal opacity which was sharply defined and which had convex margins. The opacity disappeared after one week.

Comments: The shape of this opacity was similar to that of the previous cases of paramediastinal haematoma.

\section{'LATE' CASES}

Case 8 F. F., a man aged 45, fell from a height of 14 feet $(4.2 \mathrm{~m}$.) and sustained multiple fractures of the pelvis. Ten days after the accident his temperature began to rise and after a further 10 days, in spite of treatment with antibiotics, his temperature was $101^{\circ} \mathrm{F}$. He complained of pain in the left side of the chest and had a slight haemoptysis. Haemoptyses persisted for a further two weeks and he had several transient exacerbations of high temperature and chest pain. On one occasion he had a sudden attack of heaviness, numbness, and pain in the right leg associated with marked diminution of the arterial pulsations. All his symptoms subsided and he made a full recovery. The first chest radiograph was taken three weeks after the accident, when the mediastinum was seen to be widened. There was a wedge-shaped right upper mediastinal opacity and 


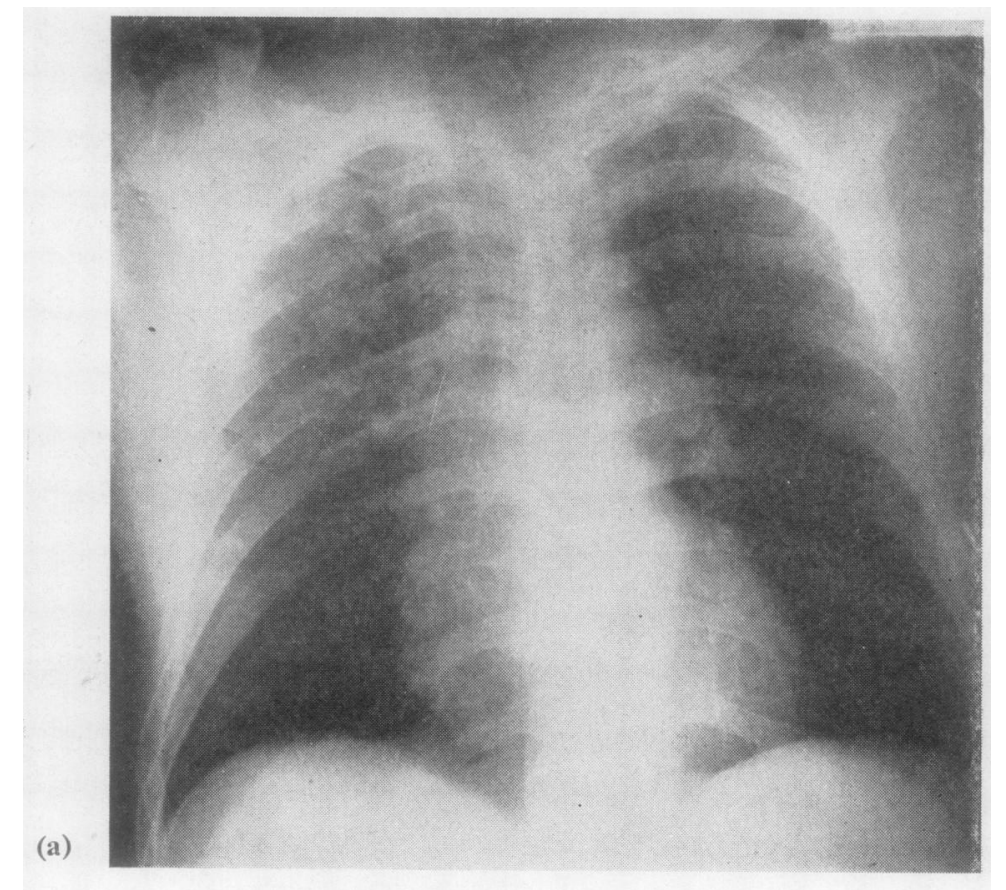

FIG. 9. Case 16. (a) Faint right paratracheal opacity. The trachea remained straight. Linear and confluent opacities in the right upper lobe. (b) The opacity is denser. The direction of the tracheostomy cannula indicates that the trachea remained straight throughout (compare with Fig. 4c). 


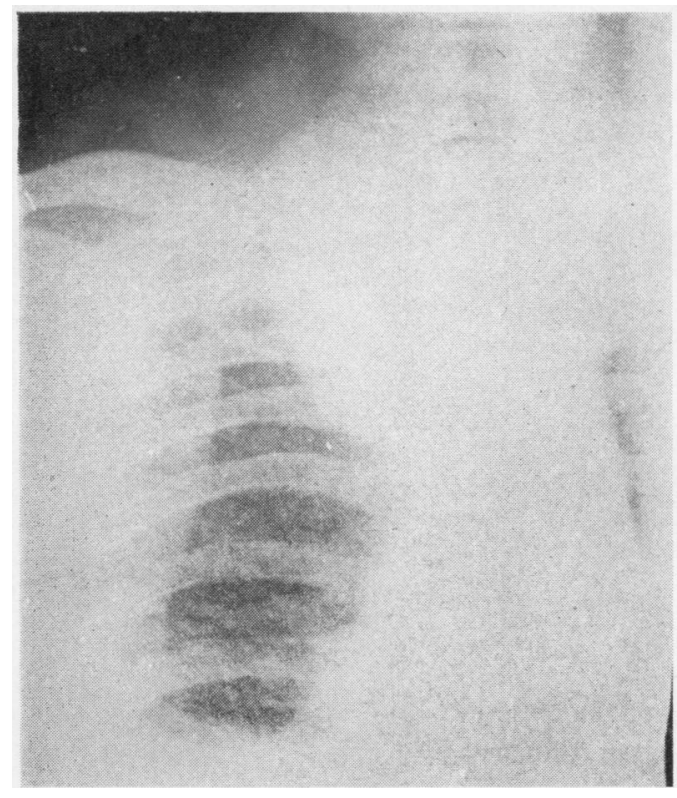

FIG. 10. Case 11. Paramediastinal haematoma. Note convex, sharply defined margins of the opacity which occupies almost the whole of the right apical region. The haematoma is crossing the clavicle and bulging into the neck because Sibson's fascia has been transected.

the aortic knuckle was still blurred. Serial films showed the gradual disappearance of the opacity.

Case 9 J.A.H., a man aged 41, was transferred from another hospital six weeks after an accident in which he sustained severe concussion, stove-in chest, and multiple fractures. He was treated with sternal fixation, clip traction of the ribs, and tracheostomy. $\mathrm{He}$ regained consciousness after one week but developed two sinuses at the site of the clip traction.

After the sinuses had been excochleated, the wounds healed in five weeks. A radiograph of the chest (six weeks after the accident) showed widening of the mediastinum. The opacity had blurred margins and there was a right upper wedge-shaped mediastinal opacity, which on serial films was seen to disappear.

Comments: The first available radiographs were taken three and six weeks after the accident, respectively. These corresponded with those films of the previous patients which were taken in the absorbing stage of mediastinal haematoma. The pattern of disappearance was also similar.

\section{DISCUSSION}

During five years of clinical observation the diagnosis of mediastinal haematoma was based on the radiological sign of a widened mediastinum which appeared after major trauma and dis- appeared later on. This was confirmed by previous radiographs (when available) and by late followup films.

On serial radiographs the same technique was used in every patient, and the films were therefore comparable. The opacities changed their shape and disappeared according to the same characteristic pattern. Absorption was fairly quick and haematomata of moderate size disappeared within one week. Large haematomata took some weeks to disappear and often left a "right upper wedgeshaped mediastinal opacity" for a considerable time.

Bleeding may arise at various sites and from various sources. The blood could secondarily find its way into the mediastinum (cases 3 and 6), or could be paramediastinal in situation (cases 10 . 11 , and 12), yet on the radiographs widening of the mediastinum was seen. In all these cases the trachea had a straight course throughout. It was therefore concluded that the haematoma could neither have a significant pressure, nor could it arise even from near the aorta. For the same reason, there was no need to differentiate the opacity from T.R.A. in the two 'late' cases (cases 8 and 9). However, extensive haematomata caused serious complications (case 16), even death (case 3 ). The straight course of the trachea only excluded T.R.A. and these cases were therefore included in one group (group C).

In a number of patients the supracarinal part of the trachea was seen to be deviated to the right, as was first noted in case 4 , who had a partial tear of the aorta (Fig. 2a). All these patients had a large haematoma, and the opacity included the aortic knuckle and often the right border of the heart. The films were very similar to, sometimes indistinguishable from, those of known cases of T.R.A. Bleeding had evidently arisen from the left side, at the level of the aortic arch and with considerable pressure. Only when the opacity was diminishing and the trachea was seen to return to its central position could T.R.A. be excluded. It was believed that in these cases (cases 5, 7, 13, 14 , and 15 ) bleeding arose from the small branches of the aorta (bronchial, oesophageal, or intercostal), as found at necropsy in case 1 (group B).

ANATOMICAL INTERPRETATION The great branches of the aortic arch are situated in such a way that the front, the left anterior, and the left side of the trachea are only supported by them. The pressure of the haematoma displaced the trachea and oesophagus to the right and the blood could spread behind them upwards and to the right. 
When bleeding was more superficial or arose from the tributaries of the superior vena cava, blood spread around this structure and was driven upwards by the pulsations of the heart and aorta to places where these pulsations were less palpable. Blood was first dispersed from the level of the aortic arch ('waist' formation). When the 'waist' was complete the 'right upper wedgeshaped opacity' developed (Fig. 6b) regularly during absorption of the haematoma. Further absorption was slower from the relatively quiet area below Sibson's fascia, and this opacity sometimes persisted for a longer time.

Rapid diminution of the opacity by dispersion and absorption could be seen even in the patient who had a complete tear of the aorta (Fig. 1b).

In aortic haematomata the high pressure was indicated by the sharply outlined convex borders of the opacity. This was also noted in non-aortic haematoma (case 15; Fig. 7) and was therefore not a specific sign.

In all patients, bleeding arose outside the visceral compartment. In case 3 , haemorrhagic infiltration of the subcutaneous tissues of the neck and chest became possible because the tear of the anterior common ligament and of the prevertebral fascia opened up the visceral compartment. This is the only communication between the neck and the chest (Grodinsky and Holyoke, 1938). Sibson's fascia (Cunningham's Textbook of Anatomy, $1951)$ is intimately blended with the carotid sheath (Nagy, 1962) and is a very efficient barrier between the chest and the neck; it prevents transmission of the changing intrathoracic pressure to the neck and creates a quiet area under its cupola (Corning, 1920). Operative transection of Sibson's fascia allowed only the paramediastinal haematoma of case 11 to bulge into the neck.

Clinical DATA AND COMPlications (Table) The severity of the impact was comparable in the three groups. Only in two patients was the impact 'moderate' (cases 12 and 15). One patient had no external injury, yet he had a partial tear of the aorta (case 4). Less than half the patients were conscious on arrival: this was due partly to concussion and partly to haemorrhagic shock, which was evenly distributed in the three groups.

The site of the fractures was not a decisive factor; none of group A, only two out of six patients in group $B$, but four out of eight patients in group $C$ had thoracic fractures. At the same time three patients in group B, but only two patients in group $\mathrm{C}$, had pelvic fractures. It appeared, therefore, that transmitted force was at

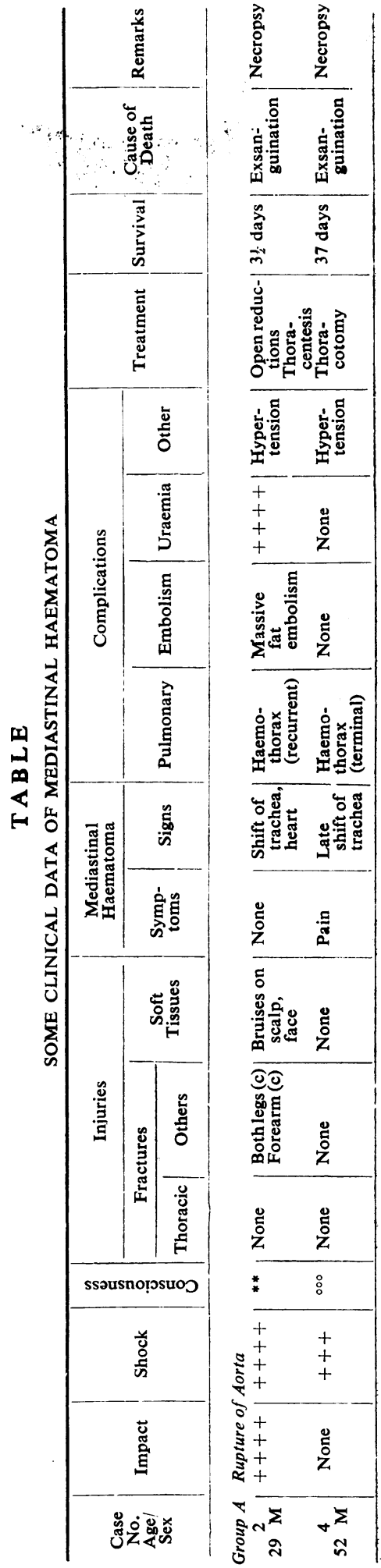




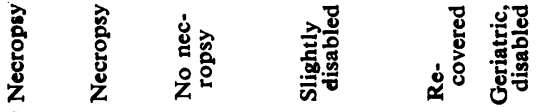

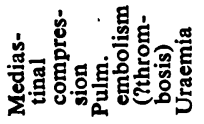

曹高旁, n

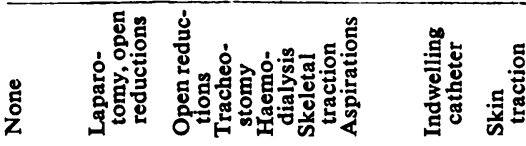

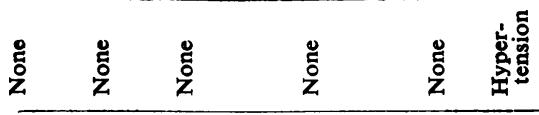

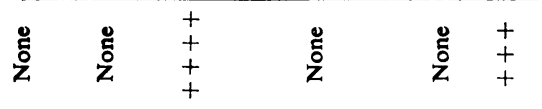

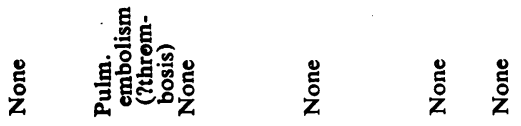

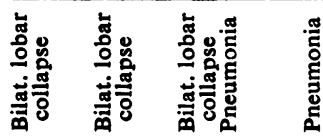

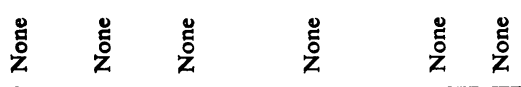

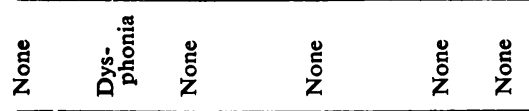

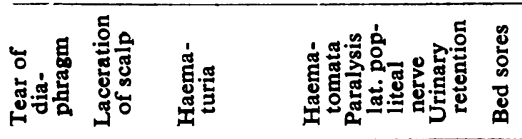

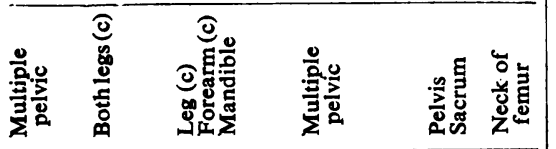

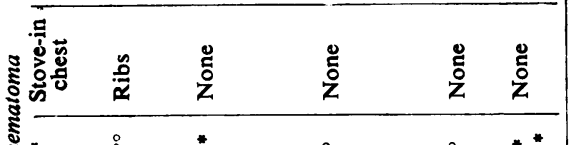

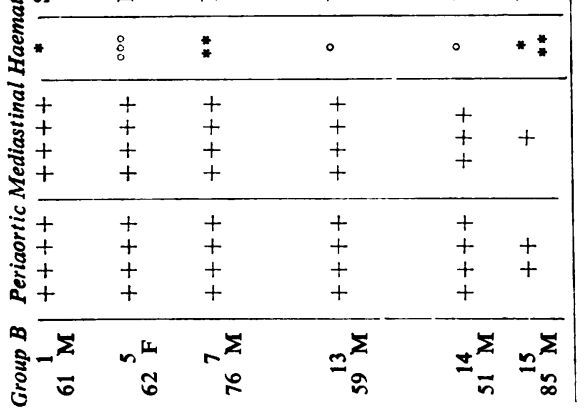

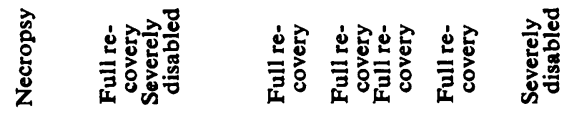

范

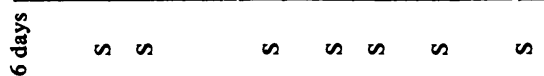

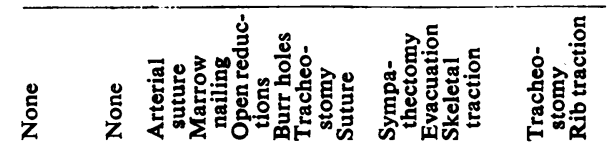
1 1

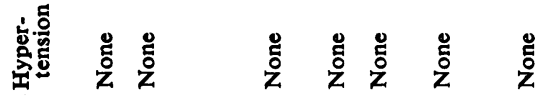

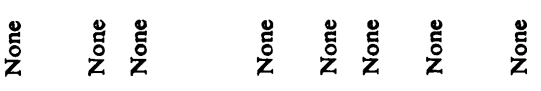

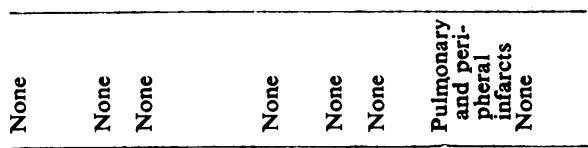

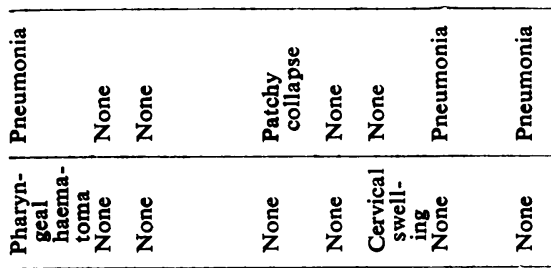

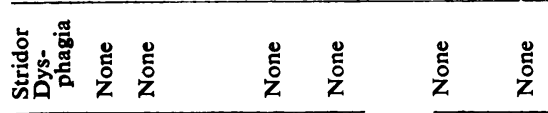

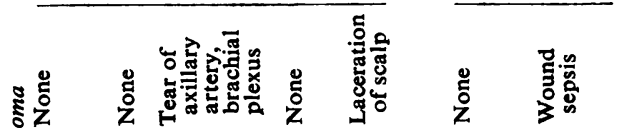

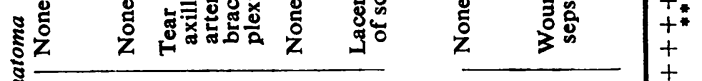

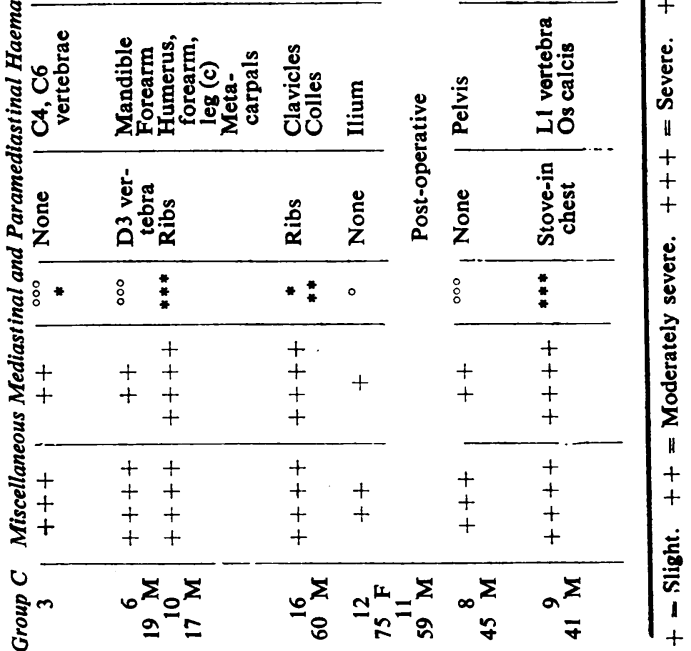


least as much responsible for major mediastinal haematoma as a local impact.

Shift of the cervical trachea associated with mediastinal haematoma was a diagnostic sign of T.R.A. in one case. In no other patient was this combination found.

Transient dysphonia was the only clinical sign of non-aortic mediastinal haematoma (case 5). Stridor, dysphagia, and pharyngeal haematoma were signs of the cervical vertebral fracture (case 3). A paucity of clinical signs was emphasized by all authors.

Three out of the six patients in group B, but only one out of eight patients in group C, died. However, only two patients in group $\mathrm{C}$, but all the patients in group B, had a large haematoma.

In non-aortic mediastinal haematoma their size and extent was primarily responsible for the complications and death, independently from their source.

The mediastinum can accommodate a surprisingly large amount of blood, and death may be caused by mediastinal compression (case 1 of AlNaaman, 1959 ; Sandor and Cooke, 1964), though I believe that a much less voluminous mediastinal haematoma may be fatal by pressure on the vagi (case 3).

Unaccountable blood loss may cause difficulties in resuscitation and may simulate rupture of the spleen as in our case 5. Blood loss may be fully evident after some days by haemodilution (case 15).

The bulk, extent, and pressure of the mediastinal haematoma interfere with ventilation and the lymphatic and venous drainage of the lungs (Kastl, 1953). Large haematomata predisposed to congestion (case 3), lobar collapse (cases 5, 7, and 14), infection (case 8), and pneumonia (cases 3 , $7,8,9,13$, and 14).

Air hunger in cases 13 and 14 persisted for one week, though the blood loss had been replaced. Case 16 became unconscious due to anoxia. All those who had a large haematoma, including the 'late' cases, had serious pulmonary complications. Haemothorax occurred only in the two patients who had a T.R.A.

Thrombo-embolic complications were possibly connected with the pressure effects of the mediastinal haematoma. There was unresolved collapse of both lower lobes, and the third and fourth grade branches of both pulmonary arteries were full of clots in case 5, who died four weeks after the accident. This was probably the result of ascending pulmonary thrombosis rather than embolism, the source of which was not found.
Hypertension and uraemia were recorded by Rice and Wittstruck (1951), Zehnder (1960), and Malm (1961), and explained by generalized vasoconstriction due to neurogenic stimulation or by disturbance of the baroreceptors in the wall of the aorta. Bowen and Teare (1962) recorded early uraemia in a young man who died 13 days after T.R.A., although the uraemia had resolved spontaneously one week previously. My case 2 is reminiscent of this. Case 4 had persistent severe hypertension. Case 5 had early uraemia which resolved before his anaemia had been corrected. These data may be significant. Case 7 died of uraemia; his large mediastinal haematoma was probably responsible for prolonged haemorrhagic shock and anoxia with consecutive renal damage.

SIGNIFICANCE OF MEDiastinal HAEMATOMa Out of the 14 patients in groups $B$ and $C$, the mediastinal haematoma was directly responsible for the death of two patients and indirectly, by fatal complications, for another two.

Morbidity was prolonged and exaggerated in five out of the remaining 10 patients. Only five recovered without significant complications. Blood loss and interference with pulmonary function were the immediate dangers. The haematomata rapidly absorbed, but delayed secondary pulmon- $\overrightarrow{\vec{O}}$ ary, thrombo-embolic and uraemic complications 3 still threatened life. If, however, the patients recovered no residual disability was due to the mediastinal haematoma.

The differential diagnosis of mediastinal haematoma remains a difficult problem. Spencer, $\ddot{x}$ Guerin, Blake, and Bahnson (1961) did not find $\frac{5}{3}$ any mediastinal haematoma at thoracotomy. On the other hand, T.R.A. was missed even at thoracotomy for cardiac massage (Cammack, Rapport, Paul, and Baird, 1959 ; Soots and Mar- 윽 tinot, 1962). In the case reported by Eiseman and $D$ Rainer (1958) the correct diagnosis of T.R.A. was made, but at thoracotomy only mediastinal $N$ haematoma was found; the tear was probably small or incomplete. Three weeks later a false $\mathcal{N}$ aneurysm was fully developed. This may be due $\mathrm{\omega}$ to secondary necrosis of the media (Bradford and? Johnston, 1950) or to inadequate circulation in the vasa vasorum due to the pressure of the haema- $\mathbb{D}$ toma (Goroncy, 1927 ; Thies, 1956).

There may be an 'intermediate' mediastinal 0 haematoma when the smaller branches of the $\frac{\vec{D}}{\mathbb{D}}$ aorta are torn at their origin (case 1). Binet and $\stackrel{\square}{\square}$ Langlois (1961) reported a case where the initial $\stackrel{\mathbb{Q}}{\circ}$ haemorrhage was spontaneously arrested but $\overline{2}$ later, due to secondary or intermittent haemor- 
rhage, a false aneurysm developed and perforated into the oesophagus.

\section{CONCLUSIONS}

Radiography of the chest is mandatory in every case of major trauma. If a widened mediastinum is seen, the position of the trachea can easily be ascertained by a penetrating film. Lateral films may sometimes be useful. If the trachea is straight throughout, the opacity is due to distortion or artefact or to a non-aortic haematoma.

In the presence of supracarinal deviation of the trachea to the right the advice of a thoracic surgeon should be sought on admission. Considering the relative frequency of non-aortic mediastinal haematoma immediate transport of these seriously injured patients to a sometimes distant thoracic centre is not justified. If, however, further investigations, e.g., aortography (Carlsson and Silander, 1963), etc., are necsssary, these are best performed at the thoracic centre which is specially equipped to deal with such cases.

Clinical evidence of tracheal shift associated with mediastinal haematoma is diagnostic of traumatic rupture of the aorta and the patients should be immediately transferred.

\section{SUMMARY}

The clinical and radiological diagnosis of mediastinal haematoma was made in 16 patients. Bleeding was due to rupture of the aorta in two patients, whereas in the other 14 patients the haematoma was 'non-aortic' in origin. Both patients of the former and four patients of the latter group died.

There was radiological evidence of supracarinal deviation of the trachea in six patients (group B), which could be a sign of partial tear of the aorta. In eight patients the course of the trachea was straight throughout (group C) and traumatic rupture of the aorta was immediately excluded.

The natural history, significance, and complications of M.H. are discussed. Large haematomata threatened life, whatever their origin.

Radiography of the chest is mandatory in every case of multiple major injuries.

I should like to express my deep gratitude to the late Professor A. G. R. Lowdon for his help and encouragement and for all the facilities he has made available at the Department of Surgery in the University of Newcastle upcn Tyne.
I am grateful to Mr. A. Logan for reading and criticizing this paper; to the late Mr. A. Webb-Jones for his interest and advice in many problems; to Dr. J. R. Kirby for revieuing the radiographs; to $\mathrm{Mr}$. W. C. Barnsley, Dr. David Kerr, Mr. J. Wardle, and Mr. P. R. R. Clarke for taking over cases 4, 7, 10, and 16 respectively; to Mr. J. W. M. Sutherland, Mr. W. Drummond, Mr. I. W. Patterson, and Miss Rowling, of the Kirkcaldy General Hospital, and to Mr. H. M. Grant, the late Mr. W. Irving, Mr. F. Moore, and Dr. M. J. Keating, of the Hartlepools Hospital, for their part in the treatment of these patients; to the late Dr. N. Grant Leitch and to Dr. R. T. Cooke for the necropsy reports ; and to Dr. Duncan Kerr, of West Hartlepool, and the Photography Department of the Medical School, University of Newcastle upon Tyne, for the illustrations.

\section{REFERENCES}

Al-Naaman, Y. D. (1959). Acute compression of the mediastinum by a hematoma. Amer. J. Surg., 98, 735 .

Binet, J. P.. and Langlois, J. (1961). Les ruptures traumatiques de l'aorte thoracique a paroi saine. J. Chir. (Paris), 82, 607.

Bowen, D. A. L., and Teare, R. D. (1962). Delayed traumatic rupture of aorta. Thorax, 17, 150.

Bradford, B., Jr., and Johnston, F. L. (1950). Traumatic rupture of the aorta. Surgery, 28, 893.

Brown, N., Tomsykoski, A. J., and Stevens, R. C. (1953). Mediastinal hemorrhage secondary to uremia. Amer. J. Med., 15, 588.

Cammack, K., Rapport, R. L., Paul J., and Baird, W. C. (1959). Deceleration injuries of the thoracic aorta. Arch. Surg., 79, 244.

Carlsson, E., and Silander, T. (1963). Rupture of the subclavian and the innominate artery due to non-penetrating trauma of the chest wall. A.ta chi-. scand., 125, 294.

Cohen, G. (1958). Traumatic haemomediastinum: a case report. S. Afr. med. J., 32, 298

Corning, H. K. (1920). Lehrbuch der Topographischen Anatomie. 11 th ed. Bergmann, Munich.

Coté, J., Hodgson, C. H., and Ellis, F. H. (1959). Traumatic mediastinal hematoma. Mayo Clin. Proc., 34, 264.

Cunningham's Textbook of Anatomy (1951). Ed. Brash, J. C. 9th ed. Oxford University Press, London.

Eiselsberg, A., and Gold. E. (1931). Uber das paravertebrale intramediastinale Hïmatom bei Wirbelbrüchen. Dtsch. Z. Chir., 233, 329.

Eiseman B.. and Rainer. W. G. (1958). Clinical management of posttraumatic rupture of the thoracic aorta. J. thorac. Surg., 35, 347.

Endress, Z. F. (1953). Traumatic mediastinal hematoma. Amer. J. Roentgenol.. $70,576$.

Goroncy, C. (1927). Zur Genese der Aortenrupturen, insbesondere indirekter bei Schussverletzungen. Dtsch. Z. ges. gerichtl. Med.,
10, 235 .

Grodinsky, M., and Holyoke, E. A. (1938). The fasciae and fascial spaces of the head, neck and adjacent regions. Amer.J. Anat., 63, 367.

Hanner, J. M., and Glauser, F. E. (1953). Posttraumatic mediastinal hematoma. U.S. armed Forces med. J., 4, 141.

Hollingsworth, R. K.. Johnston, W. W., and McCooey, J. F. (1952). Traumatic saccular aneurysm of the thoracic aorta. $J$. thorac. Surg., 24, 325

Horn, H. (1930). Bemerkenswerter Fall einer Stichverletzung der Art. mammaria intern. sin. mit grossem Mediastinalhämatom. Ausgang in vällige Heilung. Zbl. Chir., 57, 2550.

Kastl. W. H. (1953). Traumatic rupture of the thoracic aorta. Ann. Su:g., 137. 111.

K ̈rner, O. (1915). Ein traumatisches Hämatom im Mediastinum mit starker Verdrängung der Speise- und der Luftröhre, aber ohne Rekurrenslähmung. $Z$. Ohrenheilk., 73, 33 . Laforet. E. G. (1955). Traumatic hemomediastinum. J. thorac. Surg.,
29, 597.

Le Brigand, H., Binet. J. P.. and Langlois, J. (1961). Les lésions traumatiques du médiastin. Acta chir. belg., 60, Suppl. 2, p. 92.

Longin, F. (1955). Traumatisches. paramediastinales Haematom ohne nachweisbare Fraktur. B'uns' Beitr. klin. Chir., 190, 245.

Malm. J. R. See Spencer et al.: Discussion, p. 97. Murdock. C. E. (1957). Traumatic rupture of the aorta. Arch. Surg.,
74, 539. 
Nagy, D. (1962). Chirurgische Anatomie. Thorax, 4th ed. Akadémiąi Kiado, Budapest.

Passaro, E., and Pace, W. G. (1959). Traumatic rupture of the aorta. Surgery, 46, 787.

Rice, W. G., and Wittstruck, K. P. (1951). Acute hypertension and delayed rupture of the aorta. J. Amer. med. Ass., 147, 915.

Sandor, F., and Cooke, R. T. (1964). Spontaneous cervico-medias tinal haematoma. Brit. J. Surg., 51, 682.

Schmitt, H. G. (1940). Rundschatten auf der Lunge, durch Hämatome hervorgerufen. Röntgenpraxis, 12, 332.

Soots, G., and Martinot, M. (1962). Rupture traumatique de l'aorte thoracique. Lille chir., 17, 250.

Spencer, F. C., Guerin, P. F., Blake, H. A., and Bahnson, H. T. (1961) A report of 15 patients with traumatic rupture of the thoracic aorta. J. thorac. Surg., 41, 1.
Thies, W. (1956). Veränderungen der Aurtenmedia nach Tod im akuten Kollaps. Beitr. path. Anat., 116, 461.

Thomas, P. A., and Keeling, W. M. (1956). Traumatic hemomediastinum. Arch. Surg., 73, 316.

Vincent, E., Roche, L., and Michel, R. (1953). L'hemomédiastin traumatique. Ann. Méd. lég., 33, 107.

Williams, J. R. (1959). Traumatic mediastinal hematoma. U.S. @ armed Forces med. J., 10, 1405.

Wyman, A. C. (1953). Roentgenologic diagnosis of traumatic rupture $\mathscr{C}$ of the thoracic aorta. Arch. Surg., 66, 656.

Zehnder, M. A. (1960). Symptomatologie und Verlauf der Aorten-: ruptur bei Geschlossener Thoraxverletzung, an Hand von 12 Fảllen. Thoraxchirurgie. 8, 1.

Zimmerman, L. M. (1936). Traumatic mediastinal hemorrhage. Amer. J. Surg., 31, 170 